the grass was literally burnt off the earth, and the mortality among stock was great. The railway trains carried supplies of water from lakes and rivers to all stricken points along the lines, selling it at the rate of twenty-five cents a thousand gallons. The water supply of many towns entirely failed, the inconvenience experienced was acute everywhere, and many agriculturists were ruined.

"All through our own South the drought has been remarkable in its length, and some odd situations have occurred. In Kentucky the beds of many streams that have never before been dry are now full of dust, the mud having become baked hard, and then broken by the wind. At Uniontown, Kentucky, the Ohio was so low that an old coal vein under the river-bed was worked, and thousands of bushels of coal were taken out. In many places along the Ohio, Mississippi, and other streams, old wrecks have been uncovered by the lowering of the water, and the residents along the banks have recovered lots of more or less valuable cargo, and junk. At Milton, Kentucky, there is a large sandbar on which many a barge of coal has struck and foundered. This bar was entirely uncovered recently, and the people living near by went to work with ordinary field ploughs and turned up tons of coal. In Maine and other eastern States the drought has been severe. The ice crop promises to be short, because lots of lands have gone almost dry, and there is no water to freeze. These general conditions have existed all over the continent, and in the north-west the situation is as bad as in the east and south."

\section{The Pressure of a Saturated Vapour as an Explicit Function of the Temperature.}

IN NATure (October 24), Mr. Donnan observed that the "Law of Diameters" in combination with any equation of state, such as Van der Waal's, which applies to the region of coexistence of liquid and vapour, supplies an (empirical) expression for the maximum pressure of a vapour at any temperature $\mathrm{T}$ in the form of an explicit function of this temperature and known constants.

Led by the same thought, I have found the equation for the vapour tension.

The "Law of Diameters," in combination with the law of Maxwell-Clausius and the equations :

$$
\begin{aligned}
\zeta_{1}+\zeta_{2}+\zeta^{\prime} & =3 \zeta_{\kappa} \\
\zeta_{1} \zeta_{2} \zeta^{\prime} & =\frac{p}{a c}
\end{aligned}
$$

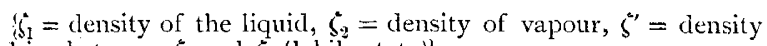
lying between $\zeta_{1}$ and $\zeta_{2}$ (labile state)\}

gives me

$$
p=\mu \frac{\left(\mathrm{T}-\mathrm{T}_{0}\right)^{3}\left(\frac{\mathrm{T}_{\kappa}}{\mathrm{T}_{0}}-\frac{\mathrm{T}_{0}}{\mathrm{~T}_{\kappa}}\right)}{\mathrm{T}^{\frac{3}{\mathrm{~T}_{k}-{ }^{4} \mathrm{~T}_{0}}}}
$$

$\left\{T_{0}=\right.$ temperature, at which the tension of vapour is nil. $\}$ $T_{\kappa}=$ critical temperature.

The method of Mr. Donnan gives:

$$
p=3 p_{\kappa} e^{\mathrm{I}-\frac{\mathrm{T}}{\mathrm{T}_{\kappa}}}\left\{\frac{24}{27} \frac{\mathrm{T}-\mathrm{T}_{0}}{3 \mathrm{~T}_{\kappa}-2 \mathrm{~T}_{0}-\mathrm{T}}-\frac{\left(\mathrm{T}-\mathrm{T}_{0}\right)^{2}}{\left(\mathrm{~T}_{k}-\mathrm{T}_{0}\right)^{2}}\right\} .
$$

If the "Law of Diameters" were consistent with the equation of state, the formulae would be the same.

Schiedam, Holland, October.

\section{Metallic Resistance and Radiation.}

A RESUlT published by Dr. Aschkinass, to the effect that the electrical resistance of thin metallic sheets like tinfoil is affected by the impact of radiation (electric waves), is often quoted; but, so far as I know, it has not been confirmed. My own experience tends to disprove it; but if any one has succeeded in confirming it, perhaps they would give us the benefit of the information. It is easy, of course, to get spurious effects with bad joints, in accordance with the discovery of Branly; and I see in your "Notes" (p. 6o) to-day, that a Japanese experimenter, Mr. Mizuno, is of the same opinion.

November 22.

Oliver J. LODGe.

\section{"L'Arithmétique Amusante."}

In the review of the above book (NATuRE, November 7), mention is made of the curious fact that $8 \times 123456789+9=$ NO. $136 \mathrm{I}$, VOL. 53$]$
987654321 . It may be of interest to point out that this is not an isolated numerical curiosity, but is, I find, one of a group of similar curiosities which are included in the following easily proved theorem.

If the number formed by writing down in ascending order beginning with unity the first $n$ digits of any scale whose radix is $r$ be multiplied by $r-2$, and $n$ be added to the product, the result is equal to the number formed by writing down in descending order the last $n$ digits of the scale beginning with the last.

William Lucas.

Mr. LuCAS's theorem is quite correct: the cases for $r=10$ have been given by E. Lucas in his "Théorie des Nombres," $i$ p. 28 , as well as (if I remember rightly) in the "Arithmétique Amusante." M. E. Lucas was probably acquainted with the general theorem; whether he published it, or whether it has ever been published, I cannot say.

Upper Bangor, November 19.

G. B. Mathews.

\section{The Society of Medical Phonographers}

Tiue address of Dr. Gowers on "the art of writing in relation to medical and scientific work," delivered to the Society of Medical Phonographers, which was mentioned in your issue of August 8, and was published in the British Medical Journal for October 7 , has been reprinted by the Society. There are a few spare copies, and any scientific worker, who is interested in the subject, can obtain one by sending a penny stamp to $\mathrm{Mr}$. Wm. Holmes, printer, Ulverston.

It may be of interest to state that the number of members of the Society is now 202. I shall be glad to know the name of any scientific worker who uses shorthand.

Warneford Asylum, Oxford, November 22 James Neil, Hon. Sec.

\section{THE ROYAL COMMISSION ON SECONDARY} EDUCATION.

${ }^{\top} \Gamma$ would be difficult to produce a document more typically English than this Report, dated August I3, 1895, of the Royal Commission appointed on March 2, I894, "to consider what are the best methods of establishing a well-organised system of secondary education in England, taking into account existing deficiencies, and having regard to such local sources of revenue, from endowment or otherwise, as are available, or may be made available, for this purpose, and to make recommendations accordingly."

That our country does not possess even an approach to a system, let alone a well-organised system, of secondary education, is in itself a sufficiently remarkable circumstance ; but some may think it even more remarkable that, having recognised this, a task so difficult as that before the Royal Commissioners should have been entrusted so recently as last year to persons who, however worthy individually, as a body but very imperfectly represent the vast interests involved in such an enquiry. More than a quarter of a century has now elapsed since the publication of the report of the Schools Enquiry Commission appointed in 1864 , and in the interval science has not only advanced with giant strides, but has also been applied to industrial purposes to an extraordinary extent, with the result that a revolution has taken place affecting not only all our actions, but our very modes of thought also, and requiring us to take cognisance of many entirely novel conceptions and considerations. Meanwhile also, our national prosperity has received a most severe check through the competition of those who have been quicker than ourselves to avail themselves of scientific discoveries and methods of working; and the probability is great that such competition will rapidly increase in severity and become unbearable unless we, as Huxley said, "organise victory" - to do which, however, we must march very fast, as we have both to overtake those who are already far ahead of us, as well as go quickly when we come up with them. It was therefore imperative that in considering the organisation of 